Dr. Rudolf Ullmark : President and Dr. J.L. Blonstein. General Secretary of The Medical Commission. A. I. B. A.

\title{
COMMENTARY.
}

It will be seen that the majority of bouts were won on points. (65. 25\%). There were a number of cuts in the region of the brow, but we think this was caused by the tough leather of the gloves supplied.

It is to be noted that in 259 matches there was only one fracture, and this was not a typical Bennett's fracture.

It is very rare to have a detached retina at amateur boxing. This is only the fourth case we have seen in 35 years of medical supervison.

It is interesting that in the 18 knock-outs the longest period of unconsciousness was only three minutes, and no boxer complained of headache, vomiting or amnesia following his bout. Normally a knock-out following a blow to the solar plexus is not accompanied by unconsciousness, but in the one case the boxer was unconscious for 20 seconds.

We feel that the percentage of injuries in 259 matches boxed under such tension and keenness as the Olympic Games is very low.

\section{MEDICAL REPORT.}

1. 287 boxers from 59 nations weighed in.

2. There were 259 matches.

3. Won on points : 169 .

4. Won by retirement : 2 . 
5. Won by RSC : (a) Outclassed - 34 (b) Injury - 19.

6. Won by disqualification : 13 .

7. Won by K.O. : 18 .

8. Won by W.O. : 4 .

SUMMARY OF INJURIES WITH AND WITHOUT INFLUENCE ON THE MATCH RESULT

1. Cuts of eyebrows : 33 .

2. Fractured thumb : 1 .

3. Detached retina : 1 .

South paw boxers : 40.

ANALYSIS OF K. Os.

1. Match 15. 2nd round. Full recovery of consciousness after 12 secs.

2. Match 23. 1st round.

ditto

13 secs.

3. Match 25. 1st round.

ditto

20 secs.

4. Match 33. 1st round.

ditto

15 secs.

5. Match 36. 2nd round.

ditto

13 secs.

6. Match 77. 3rd round.

ditto

180 secs.

7. Match 78. 1st round.

ditto

15 secs.

8. Match 106. 1st round. (Solar Plexus) ditto

20 secs.

9. Match 171. 3rd round.

ditto

17 secs.

10. Match 183. 1st round.

ditto

13 secs. 
11. Match 198. 1st round. Full recovery of consciousness after 20 secs.

12. Match 211. 1st round.

ditto

16 secs.

13. Match 223. 2nd round.

ditto

15 secs.

14. Match 224。1st round.

ditto

20 secs.

15. Match 233. 2nd round.

ditto

25 secs.

16. Match 247. 3rd round.

ditto

20 secs.

17. Match 248. 1st round.

ditto

60 secs.

18. Match 257. 1st round.

ditto

60 secs.

Total number of K. Os. $\ldots . \quad \ldots \quad \ldots \quad 18$.

Average number of $\mathrm{K}$. Os. One in every 14 contests.

No boxer was unconscious for more than three minutes.

Average periods of unconsciousness - 31 seconds. 